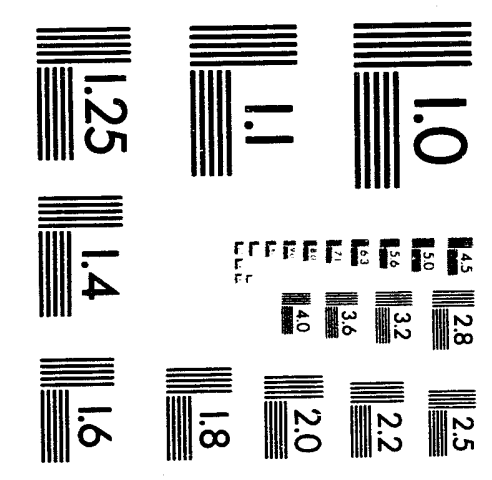



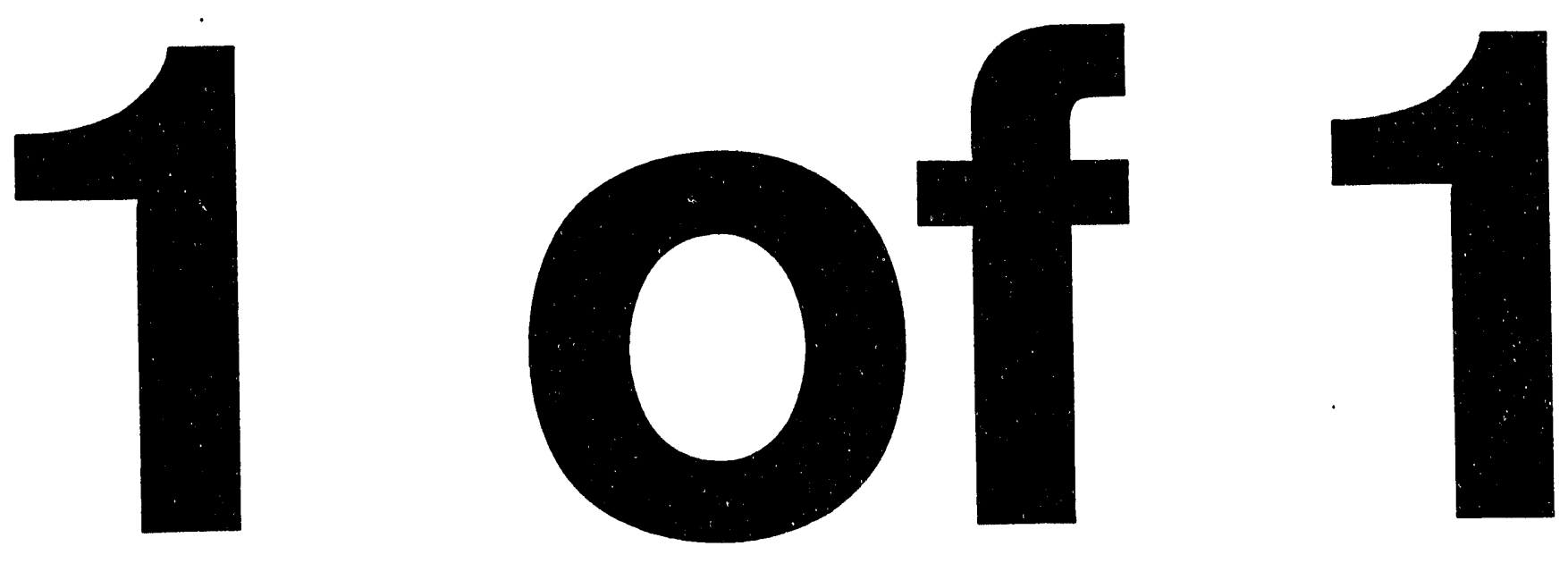


\title{
Scaling Laws for TEXT Plasma Profiles
}

\author{
S.C. McCool, R.V. Bravenec, D.L. Brower*, J.Y. Chen, \\ M.S. Foster, W.L. Li, A. Ouroura, P.E. Phillips, B. Richards, \\ K.W. Wenzel, Z.M. Zhang \\ University of Texas Fusion Research Center \\ *Department of Electrical Engineering and Institute of Plasma and Fusion \\ Research, University of California / Los Angeles, Los Angeles, CA 9()()24
}

\begin{abstract}
Regression analysis has been performed on a number of measured profiles including temperature and density vs. nominal macroscopic operating parameters for TEXT tokamak (pre-upgrade) ohmic plasmas. The resulting simple empirical model has enabled us to quickly approximate profiles of electron temperature and density, ion temperature, and soft x-ray brightness, as well as the scalar quantities: total radiated power, $\mathrm{q}=1$ radius, sawtooth period and amplitude, and energy confinement time as a power law of toroidal field, plasma current, chord average density, and fueling gas atomic weight. The model profiles are only applicable to the plasma interior, i.e. within the limiter radius. In most cases the predicted model profiles are within the experimental error bars of measured profiles and are more accurate at predicting profile variation for small operating parameter changes than the measured profiles.
\end{abstract}

\section{DISCLAIMER}

\footnotetext{
This report was prepared as an account of work sponsored by an agency of the United States Government. Neither the United States Government nor any agency thereof, nor any of their employees, makes any warranty, express or implied, or assumes any legal liability or responsibility for the accuracy, completeness, or usefulness of any information, apparatus, product, or process disclosed, or represents that its use would not infringe privately owned rights. Reference herein to any specific commercial product, process, or service by trade name, trademark, manufacturer, or otherwise does not necessarily constitute or imply its endorsement, recommendation, or favoring by the United States Government or any agency thereof. The views and opinions of authors expressed herein do not necessarily state or reflect those of the United States Government or any agency thereof.
} 


\section{Introduction}

Although profiles of electron temperature and density are routinely measured on TEXT when required for transport analysis and other experiments, it is often cumbersome to make use of the profiles measured on a particular day. Also due to the necessity to build up detailed profiles over a number of shots, this information is frequently not available for experiments in which plasma conditions are changed from shot to shot. For these reasons we undertook to construct an empirical model to approximately represent the local plasma conditions given only the macroscopic operating parameters of TEXT discharges. It was found that for reasonably clean $\left(1.5<\mathrm{Z}_{\mathrm{eff}}<2.5\right)$ ohmically heated, circular, limited plasmas, an adequate description of the plasma for most purposes could be based only on the toroidal magnetic field $\mathrm{B}_{\mathrm{T}}$, plasma current $\mathrm{I}_{\mathrm{n}}$, chord average electron density, $\bar{n}_{\mathbf{e}}$, and working gas atomic mass, $A_{i}$. We performed non-linear regression analysis on up to 60 measured profiles of electron temperature and density, ion temperature, and soft x-ray brightness, as well as the scalar quantities: total radiated power, $q=1$ radius, sawtooth period and amplitude, and energy confinement time fitting to them a power law of toroidal field, plasma current, chord average density, and fill gas atomic weight.

The resulting scaling law model of TEXT plasmas is cataloged in this report. Note that the profiles on which this scaling law is based were measured on pre-upgrade TEXT with a full poloidal TiC ring limiter at $\mathrm{r}=26$ $\mathrm{cm}$. It has not been determined to what extent these profiles are applicable to TEXT-U. Also the information presented here applies to $\mathrm{H}_{2}$ discharges unless otherwise noted. The central temperature in helium plasmas for example is roughly $30 \%$ higher. The model profiles are only applicable to the plasma interior, i.e. within the limiter radius, since plasma edge and scrape-off data is not included in this analysis. In most cases the predicted model profiles are within the experimental error bars of measured profiles and are more accurate at predicting profile variation for small operating parameter changes than the measured profiles. 


\section{TEXT Scaling Laws}

In the following expressions, $\rho$ denotes a flux surface coordinate $\approx r / a$ where $\mathrm{a}=26 \mathrm{~cm}$ for the discharges on which the measured profiles were taken. To use these formulas the input parameters must be in the following units: $\mathrm{BT}_{\mathrm{T}}$ in $(\mathrm{kG}), \mathrm{I}_{\mathrm{p}}$ in $(\mathrm{kA}), \overline{\mathrm{n}}_{\mathrm{e}}$ in $\left(10^{13} \mathrm{~cm}^{-3}\right)$.

\section{Electron density profile:}

Non-linear regression was performed on 50 electron density profiles measured with the UCLA FIR interferometer ${ }^{1}$. A comparison of the resulting power laws with the measured data for hydrogen discharges is shown in Fig. 1.

$$
\begin{aligned}
& \mathrm{n}_{\mathrm{e}}(\rho)=\mathrm{ne}_{\mathrm{e}}(0) \exp \left[-\left(\mathrm{abs}(\rho / \mathrm{w})^{\mathrm{s}}\right)\right] \quad\left(10^{13} \mathrm{~cm}^{-3}\right) \\
& \mathrm{n}_{\mathrm{e}}(0)=3.858 \mathrm{BT} \cdot 213 \mathrm{Ip}-.300 \overline{\mathrm{n}}_{\mathrm{e}} \cdot 984 \quad \approx \overline{\mathrm{n}}_{\mathrm{e}} \\
& \mathrm{w}=0.351 \mathrm{BT}^{-.229} \mathrm{Ip} .300 \overline{\mathrm{n}}_{\mathrm{e}} .001 \\
& \mathrm{~s}=0.586 \mathrm{BT}^{-.876} \mathrm{Ip} .781 \overline{\mathrm{n}}_{\mathrm{e}} .052 \quad \approx 1 / \mathrm{q}
\end{aligned}
$$

\section{Electron temperature profile:}

Regression was performed on 44 measured electron temperature profiles using the ruby laser Thomson scattering system. The regression fits to the following exponential function for hydrogen discharges are shown in Fig. 2.

$$
\begin{aligned}
& \mathrm{T}_{\mathrm{e}}(\rho)=\mathrm{T}_{\mathrm{e}}(0) \exp \left[-\left(\mathrm{abs}(\rho / \mathrm{w})^{\mathrm{s}}\right)\right] \quad(\mathrm{eV}) \\
& \mathrm{T}_{\mathrm{e}}(0)=36.8 \mathrm{BT} .748 \mathrm{Ip} .205 \overline{\mathrm{n}}_{\mathrm{e}}-.319 \\
& \mathrm{w}=0.171 \mathrm{BT}^{-.484} \mathrm{Ip} .514 \overline{\mathrm{n}}_{\mathrm{e}} .021 \\
& \mathrm{~s}=0.782 \mathrm{BT}^{-.698} \mathrm{Ip} .584 \overline{\mathrm{n}}_{\mathrm{e}} .118
\end{aligned}
$$

1 "Plasma parameter dependences of the electron density profile in TEXT", W.L. Li, D.L. Brower, S.K. Kim, M. Nagatsu, C.X. Yu, W.A. Peebles, N.C. Luhmann, Jr., S.C. McCool, R.V.Bravenec, X.Z. Yang, Z.M. Zhang, Rev.

Sci. Instrum. 61 (1990) 2852. 
Comparable fits were obtained if the electron temperature profile width and shape was parameterized in terms of the safety factor $\mathrm{q}_{\mathrm{i}}$.

$$
\begin{aligned}
& w=1.02 q^{-.42} \\
& s=4.9 q^{-.64}
\end{aligned}
$$

\section{Ion temperature profile:}

Regression was performed on 87 measured central ion temperature ${ }^{2}$, as shown in Fig. 4, yielding the following expression for $T_{i}(0)$. Because of the limited spatial range of measured ion temperature profiles, the following constant width and shape parameters were found to adequately represent the measured profiles.

$$
\begin{aligned}
& \mathrm{T}_{\mathrm{i}}(\rho)=\mathrm{T}_{\mathrm{i}}(0) \exp \left[-\left(\mathrm{abs}(\rho / \mathrm{w})^{\mathrm{S}}\right)\right](\mathrm{eV}) \\
& \mathrm{T}_{\mathrm{i}}(0)=\mathrm{k}_{1} \frac{175.6 \mathrm{BT} \cdot 531 \mathrm{Ip} \cdot 363 \overline{\mathrm{n}}_{\mathrm{e}}-1.047 \mathrm{~A}_{\mathrm{i}} \cdot 292}{4.450 \mathrm{BT} \cdot 071 \mathrm{Ip} \cdot 172 \overline{\mathrm{n}}_{\mathrm{e}}-1.867 \mathrm{~A}_{\mathrm{i}} \cdot 467+1}
\end{aligned}
$$

where $A_{i}=$ atomic weight, $k_{1}=1$ for DNB shots and 0.818 for non-DNB shots.

$$
\begin{aligned}
& w \approx 0.7 \pm 0.04 \\
& s \approx 2.7 \pm 0.4
\end{aligned}
$$

\section{Total radiated power:}

Regression analysis performed on data taken with a 10 channel bolometer array 3,4 on hydrogen discharges is shown in Fig. 5.

$P_{\text {rad }}(k W)=3.99 \mathrm{Ai}_{\mathrm{i}} .313 \mathrm{BT}^{-.252} \mathrm{Ip} .798 \overline{\mathrm{n}}_{\mathrm{e}} .385$

where $\mathrm{A}_{\mathbf{i}}$ is the working gas atomic mass $=1$ for $\mathrm{H}, 4$ for $\mathrm{He}$

Total radiated power/ ohmic heating power:

2 "TEXT Scaling Laws", B. Richards, University of Texas, FRC Technical Memo 5/8/90.

3 "Bolometric Measurements on TEXT", Z.M. Zhang, R.V. Bravenec, P.M. Valanju, W.L. Rowan, Bulletin of the Am. Phys. Soc. Nov., 1989.

4 "Status of TEXT Bolometry", Y. He, R.V. Bravenec, University of Texas, Fusion Research Center Report, FRCR \#306, May 1988. 


$$
\mathrm{P}_{\mathrm{rad}} / \mathrm{P}_{\mathrm{oh}}=2.14 \mathrm{Ai}_{\mathrm{i}} \cdot 076 \mathrm{BT} \cdot 324 \mathrm{Ip}-.497 \overline{\mathrm{n}}_{\mathrm{e}} \cdot 323
$$

\section{Electron energy confinement time:}

The electron energy confinement time was determined from Thomson scattering temperature profiles and FIR interferometer density profiles. Regression analysis performed on discharges below the saturated ohmic confinement observed at high density is shown in Fig. 6. This analysis yields the following power law:

$$
\tau_{\mathrm{Ee}}(\mathrm{ms})=2.2 \mathrm{BT} 0.7 \mathrm{Ip}-.36 \overline{\mathrm{n}}_{\mathrm{e}} 1.0
$$

\section{Sawtooth period:}

Regression analysis was performed on data taken with the vertically viewing 40 channel suriace barrier diode soft $x$-ray array sensitive to soft $x$ rays in the range from 1 to $10 \mathrm{keV}$. Data for the scaling of sawtooth period with plasma parameters is shown in Fig. 7. The observed sawtooth period on TEXT ranges from 1 to $7 \mathrm{~ms}$.

$$
\tau_{s}(\mathrm{~ms})=37.3 \mathrm{BT} \cdot 38 \mathrm{Ip}-.84 \overline{\mathrm{n}}_{\mathrm{e}} \cdot 96
$$

\section{Approximate energy confinement time from soft $x$-ray data:}

An empirical scaling law for total energy confinement time based on soft $x$-ray measurements has been shown to be useful 5 . This scaling law is based on a thermal diffusivity estimated from the sawtooth inversion radius

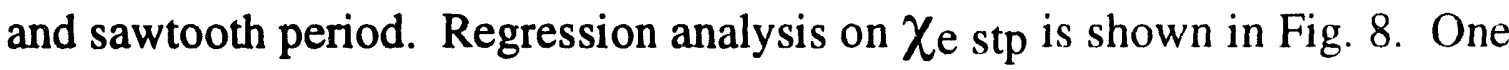
can stretch this estimate further to obtain an approximate energy confinement time from the following simple expression. This nominally total energy confinement time (including both electron and ion stored energy) has been compared to the true (electron only) energy confinement time determined from Thomson scattering temperature profiles and FIR interferometer density profiles. This surprisingly good comparison is shown

5 "A TYPICAL MHD ACTIVITY IN TEXT", R. Cross \& T. Kochanski, S. Kim, J. Snipes, University of Texas, Fusion Research Center Report, FRCR \#270, 1/12/84, and S.B Kim, Bull. Am. Phys. Soc. Nov. 1984. 
in Fig. 9. Note: $T_{i}$ is usually about $50 \%$ of $T_{e}$, hence $\tau_{E}$ should be about 1.5 $\tau_{\mathrm{Ee}}$

$$
\begin{aligned}
& \tau_{\text {E stp }} \approx \mathrm{a}^{2} /\left(4 \chi_{\mathrm{e}}\right) \\
& \chi_{\text {e stp }}=3 / 8\left(\text { rinv }_{\mathrm{a}}-\mathrm{rinv}^{2}\right) / \tau_{\mathrm{s}}
\end{aligned}
$$

$q=1$ radius from soft $x$-ray tomography:

Regression has been used to derive an empirical scaling law for the radial location of soft $x$-ray sawtooth inversion (associated with the $q=1$ surface) from the raw brightness data ( $\mathrm{rinv}$ range is from 2 to $14 \mathrm{~cm}$ ). The regression fit is shown in Fig. 10.

$$
\operatorname{rinv}(\mathrm{cm})=3.06 \mathrm{BT}^{-.95} \mathrm{Ip} \cdot 66 \overline{\mathrm{n}}_{\mathrm{e}} \cdot 10 \quad \approx 1 / \mathrm{q}
$$

Because of chord averaging, the emissivity inversion radius $(q=1)$ is actually larger by 0.8 to $1.6 \mathrm{~cm}$, with no clear dependence on $\mathrm{q}(\mathrm{a})$.

$$
\mathrm{r}_{\mathrm{q}=1}(\mathrm{~cm})=\mathrm{rinv}+1.2 \mathrm{~cm}
$$

\section{Soft x-ray peak amplitude:}

Regression analysis has been performed on the central pøak amplitude of the soft X-ray profile (in arbitrary absolute units). The regression fit is shown in Fig. 11 (a).

$$
\mathrm{A}_{\mathrm{s}} \text { (arb units) } \approx \mathrm{BT}^{1.1} \text { Ip } 1.2 \overline{\mathrm{n}}_{\mathrm{e}}-.17 \quad \approx \mathrm{BT}_{\mathrm{Ip}}
$$

(actually scales like $\bar{n}_{\mathbf{e}}-0.5$ until near the density disruption limit)

\section{Soft $x$-ray profile width (HWHM):}

Regression has also been carried out on the soft $x$-ray profile width (HWHM) for a spline fit to the profile measured with a 40 channel vertically viewing array. This regression fit is shown in Fig. 11 (b).

$$
\mathrm{w}_{\mathrm{s}}(\mathrm{cm})=0.46 \mathrm{BT}^{-.81} \mathrm{Ip} 1.0 \overline{\mathrm{n}}_{\mathrm{e}}^{-.06} \quad \approx 1 / \mathrm{q}_{\mathrm{a}}
$$




\section{Sawtooth absolute amplitude:}

A regression fit of the absolute amplitude of central soft x-ray sawteeth to a power law is shown in Fig 12 (a).

$$
\mathrm{A}_{\mathrm{st}} \text { (arb units) } \approx \mathrm{BT} \cdot 30 \mathrm{Ip} \cdot 63 \overline{\mathrm{n}}_{\mathrm{e}} \cdot 31
$$

\section{Sawtooth normalized amplitude $\left(\mathbf{A}_{\mathbf{s t}} / \mathbf{A}_{\mathbf{s}}\right)$ :}

Often the normalized sawtooth amplitude is of interest, where the absolute sawtooth amplitude is divided by the absolute peak amplitude. This yields a very different scaling with plasma parameters, as is shown in Fig. 12 (b), than the absolute sawtooth amplitude alone.

$$
\mathrm{A}_{\mathrm{st}}(\%)=2650 \mathrm{BT}-.78 \mathrm{Ip}-.55 \overline{\mathrm{n}}_{\mathbf{e}} \cdot 48
$$

\section{Conclusions:}

Non-linear regression analysis has been carried out on profiles measured on TEXT vs. the nominal macroscopic operating parameters such as toroidal magnetic field and plasma current. This analysis has yielded empirical scaling laws which can approximately predict measured profiles of electron temperature and density, ion temperature, and soft x-ray brightness, as well as the scalar quantities: total radiated power, $q=1$ radius, sawtooth period and amplitude, and energy confinement time. These scaling laws are in the form of power laws of the toroidal magnetic field $\mathrm{B}_{\mathrm{T}}$, plasma current $I_{p}$, chord average electron density, $\bar{n}_{\mathbf{e}}$, and working gas atomic mass, $A_{i}$.

These scaling laws are only applicable to the plasma interior of preupgrade TEXT for reasonably clean $\left(1.5<\mathrm{Z}_{\mathrm{eff}}<2.5\right)$ ohmically heated, circular, limited plasmas. The information presented here applies only to $\mathrm{H}_{2}$ discharges unless otherwise noted. These scaling laws have proved very useful in quickly reproducing the major features of TEXT plasmas and in some ways improve on individual measured profiles because of the inherent averaging. 


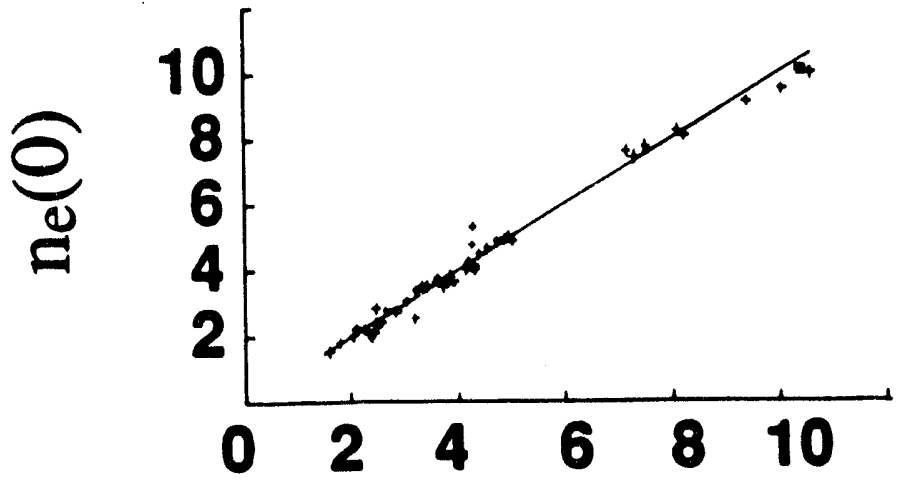

(a)

$$
3.858 \text { BT } .213 \text { Ip }-.300 \overline{n_{e}} \cdot .984
$$

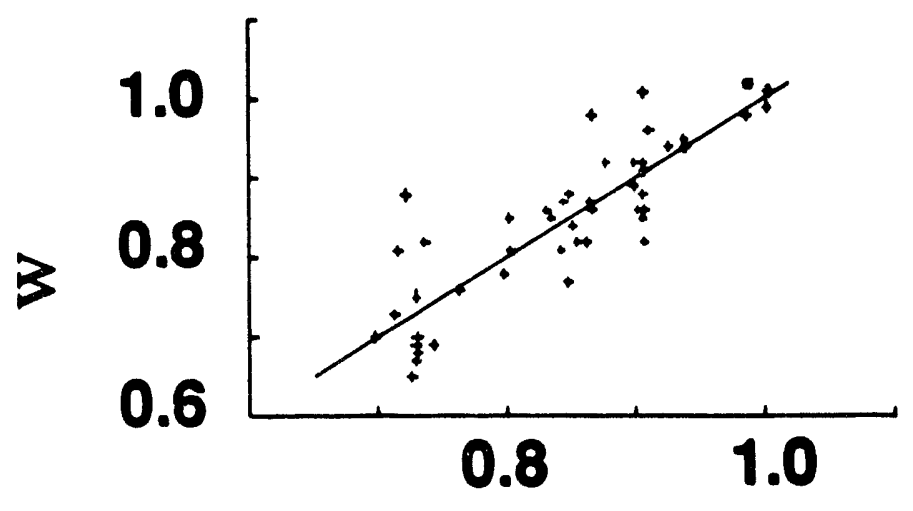

(b)

$$
0.351 \text { ВТ }-.229 \text { Ip } .300 \overline{n_{e}} .001
$$

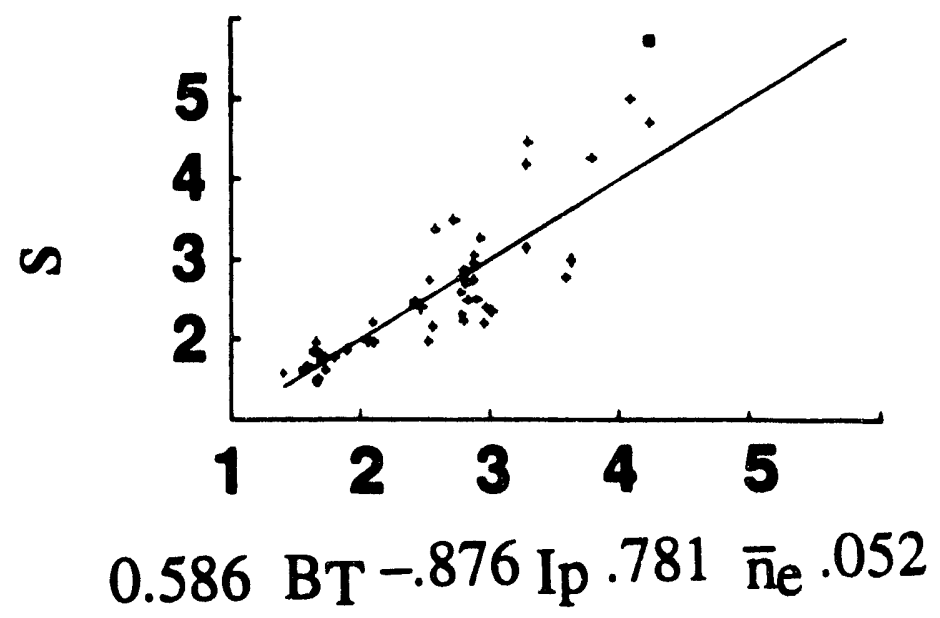

(c)

Fig. 1 Density profile regression for an exponential function with free parameters (a) central density $n_{e}(0),(b)$ normalized width $w,(c)$ shape $s$. 
a)

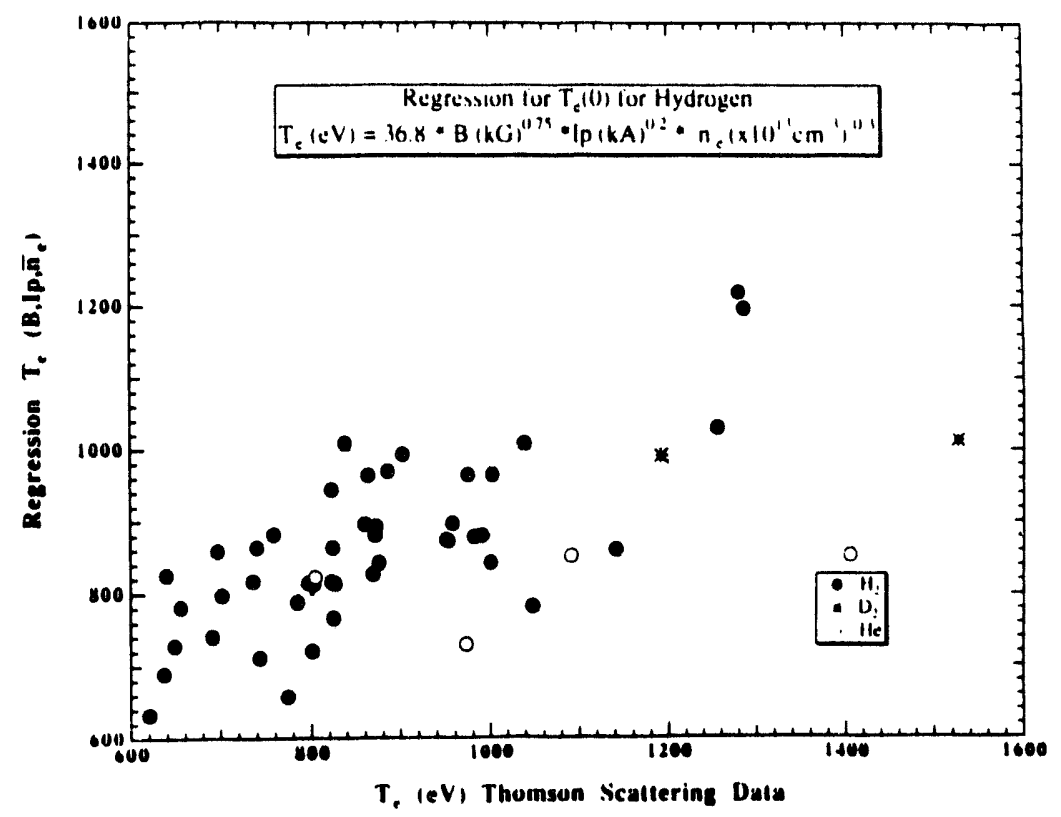

b)
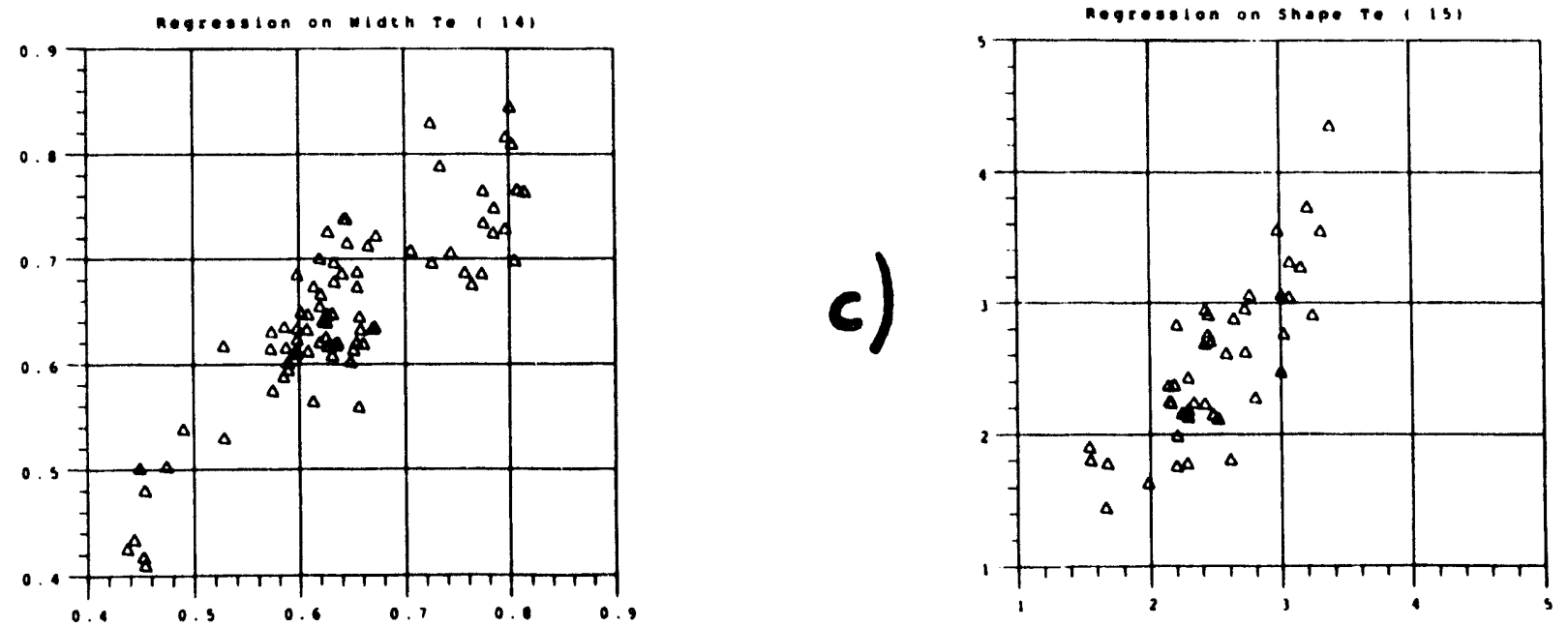

Fig. 2 Temperature profile regression for an exponential function with free parameters (a) central temperature $T_{e}(0)$, (b) normalized width $w$, (c) shape s. 

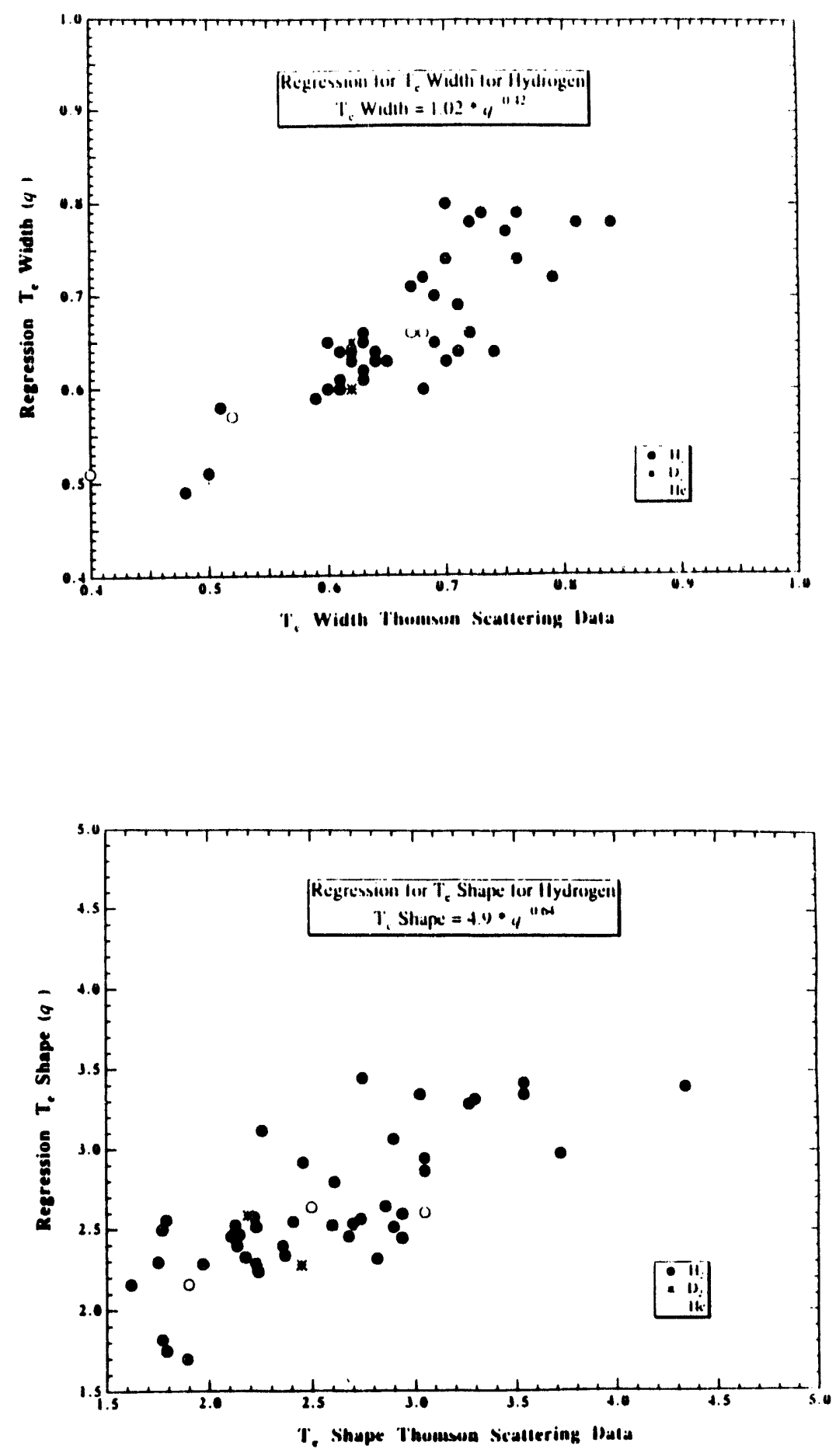

Fig. 3 Temperature profile regression as in Fig. 2 except for a power law of $q_{a}$ with free parameters (a) normalized width $w$, (b) shape $s$. 


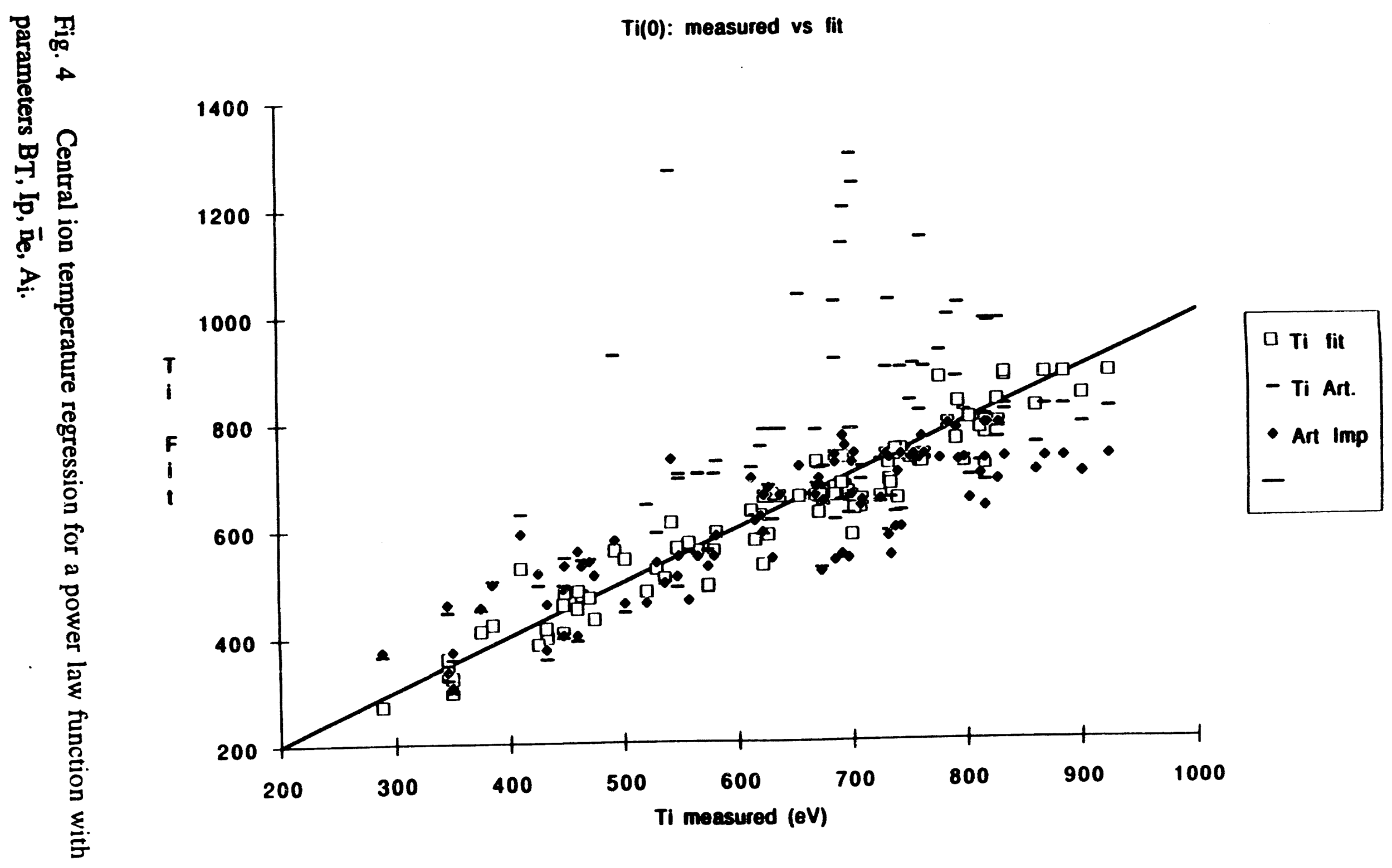


(a)

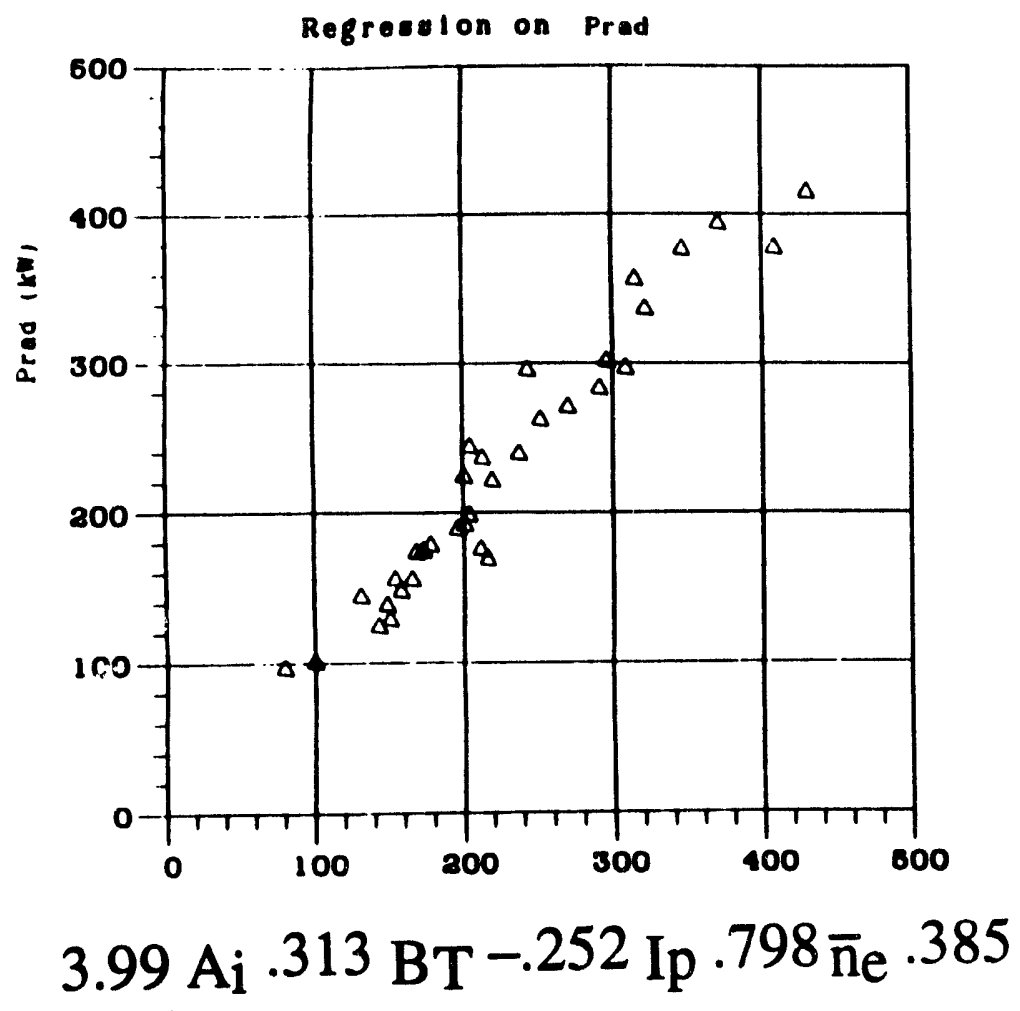

(b)

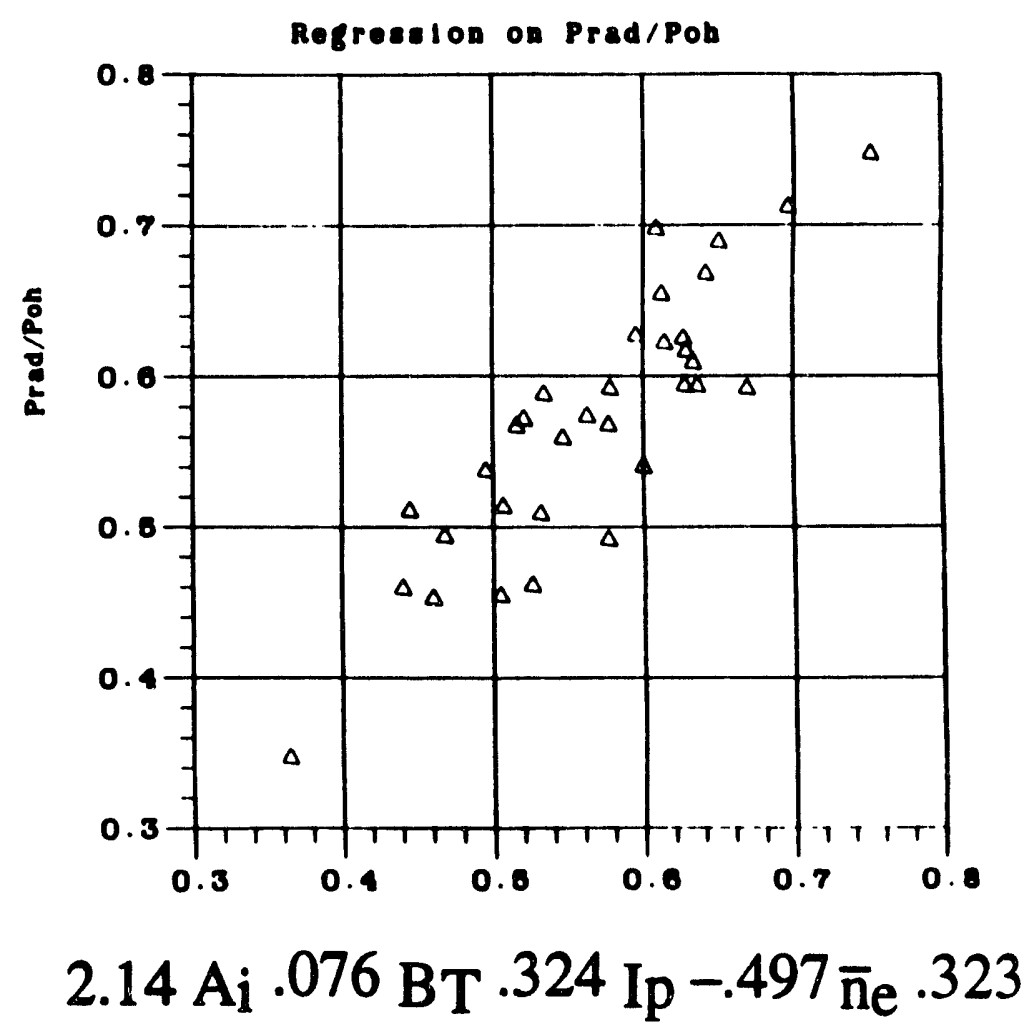

Fig. 5 Total radiated power for a power law function with parameters BT, Ip, $\overline{\mathbf{n}}$, $A_{i}$ for (a) $P_{r a d}$ and (b) $P_{r a d} / P O H$. 


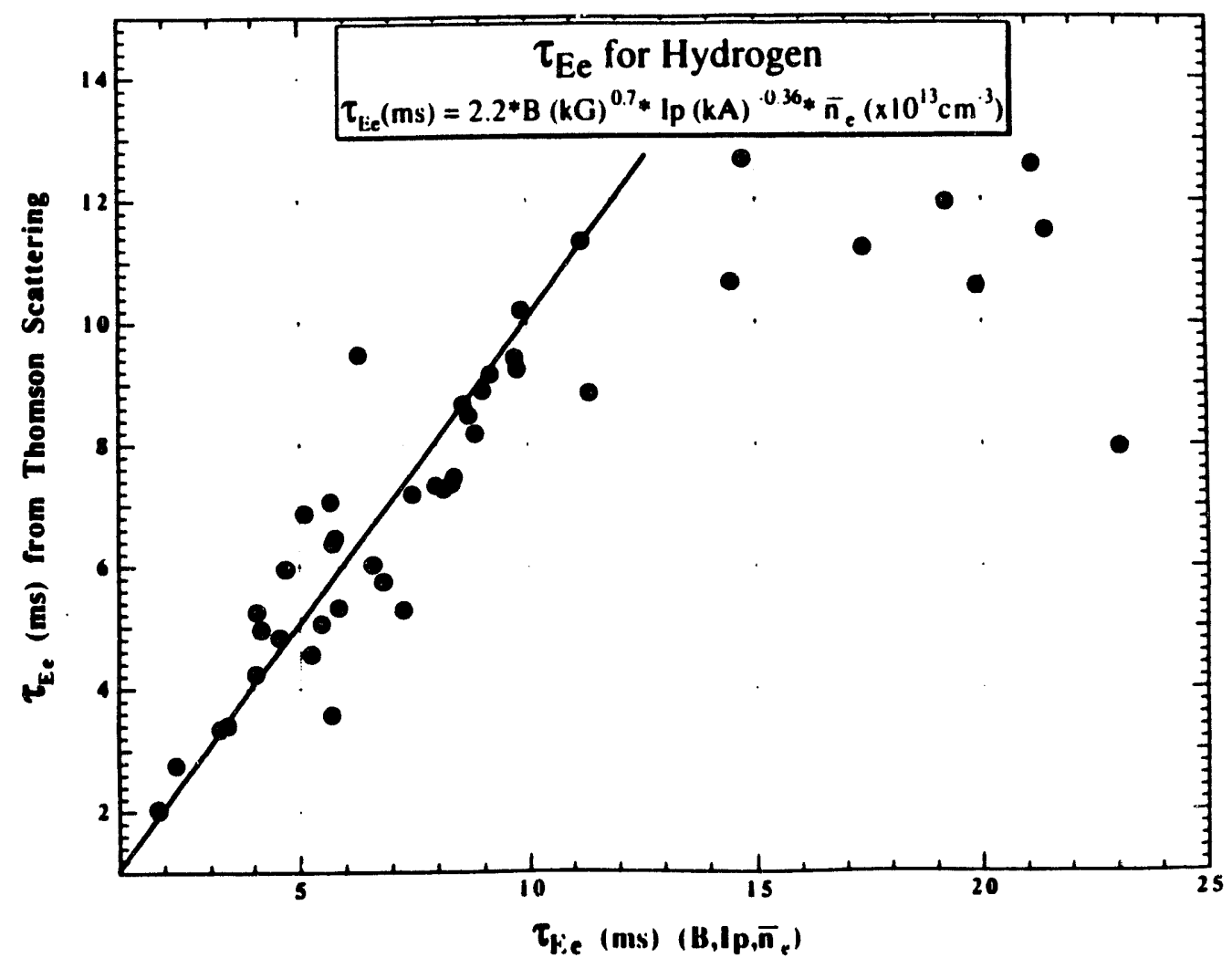

Fig. 6 Electron energy confinement time regression for a power law function with parameters BT, Ip, $\bar{n}_{e}$, fitting only low $\bar{n}_{e}$ data below the saturated regime. 


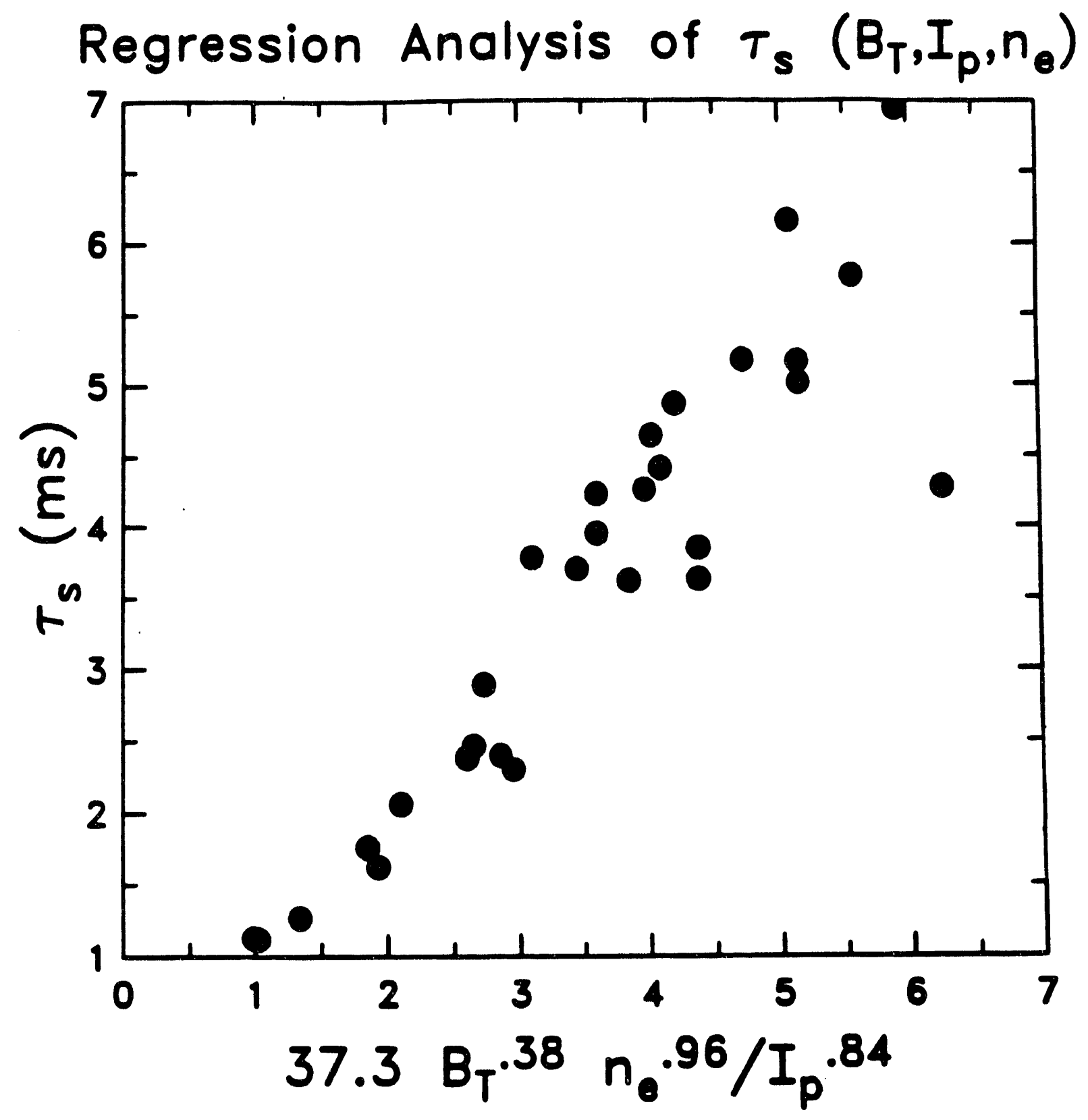

Fig. 7 Sawtooth period regression for a power law of BT, Ip, ne. 


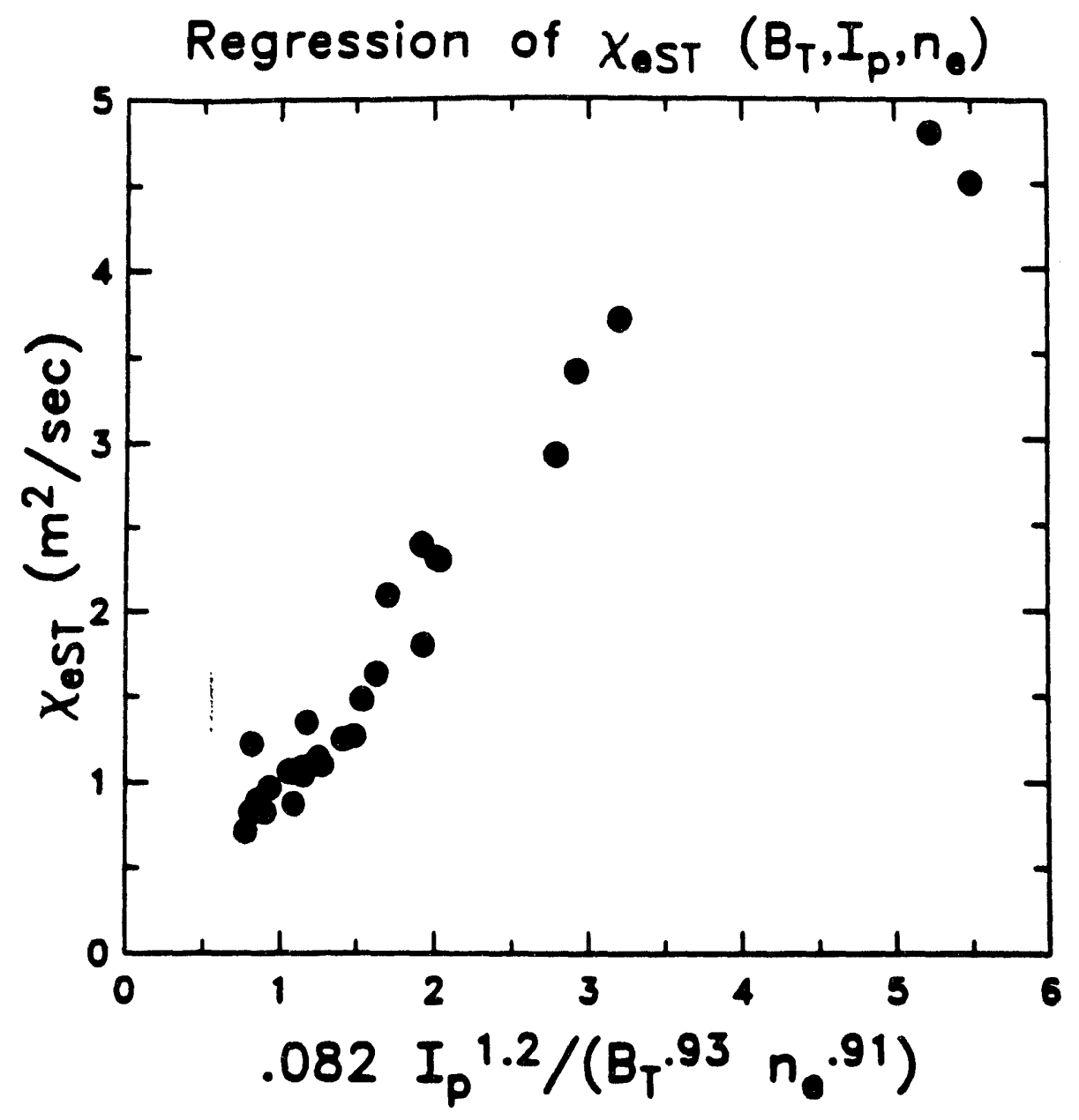

Fig. 8 Estimated thermal diffusivity $\chi_{\mathrm{e}}$ stp (from sawtooth inversion radius and sawtooth period) regression for a power law of BT, Ip, n 


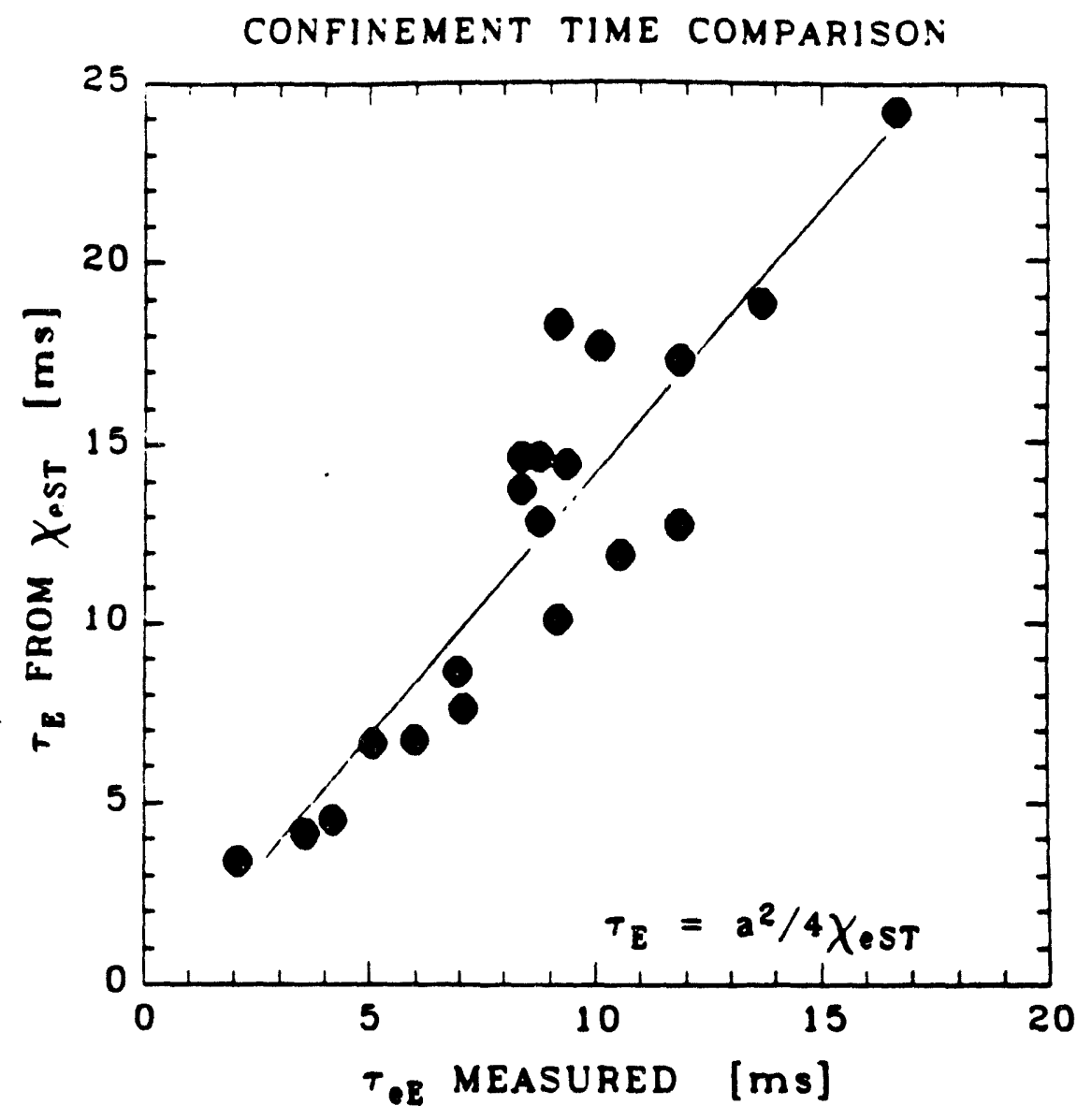

Fig. 9 Comparison of estimated total energy confinement time $\tau_{E}$ stp $\left.\approx a^{2 /(4} \chi_{e}\right)$ with electron energy confinement time determined from Thomson scattering and FIR interferometer data. 


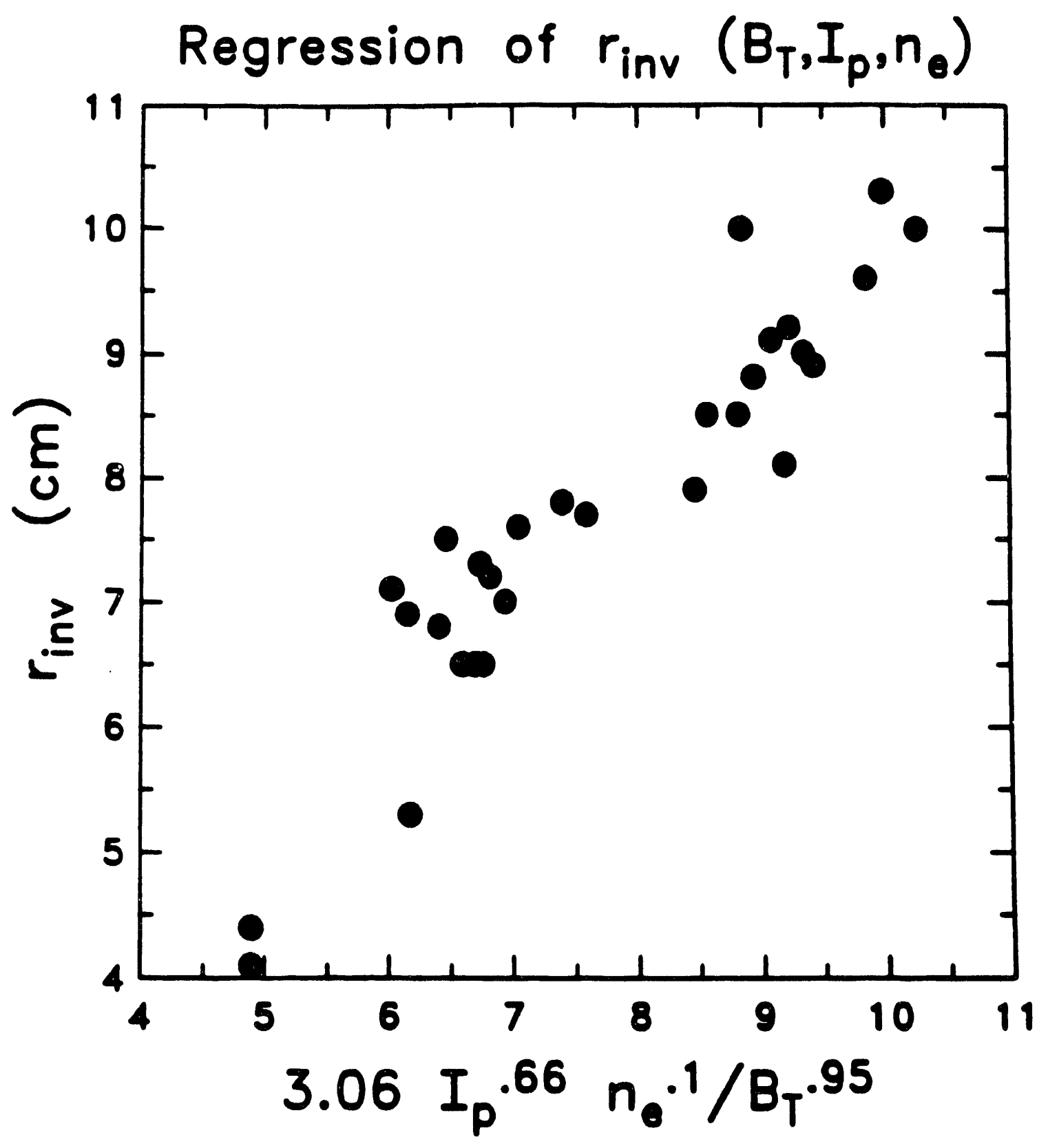

Fig. 10 Sawtooth inversion radius $r_{i n v}$ regression for a power law of BT, Ip, $\bar{n}_{\mathbf{e}}$. 
Soft X-ray Peak Amplitude

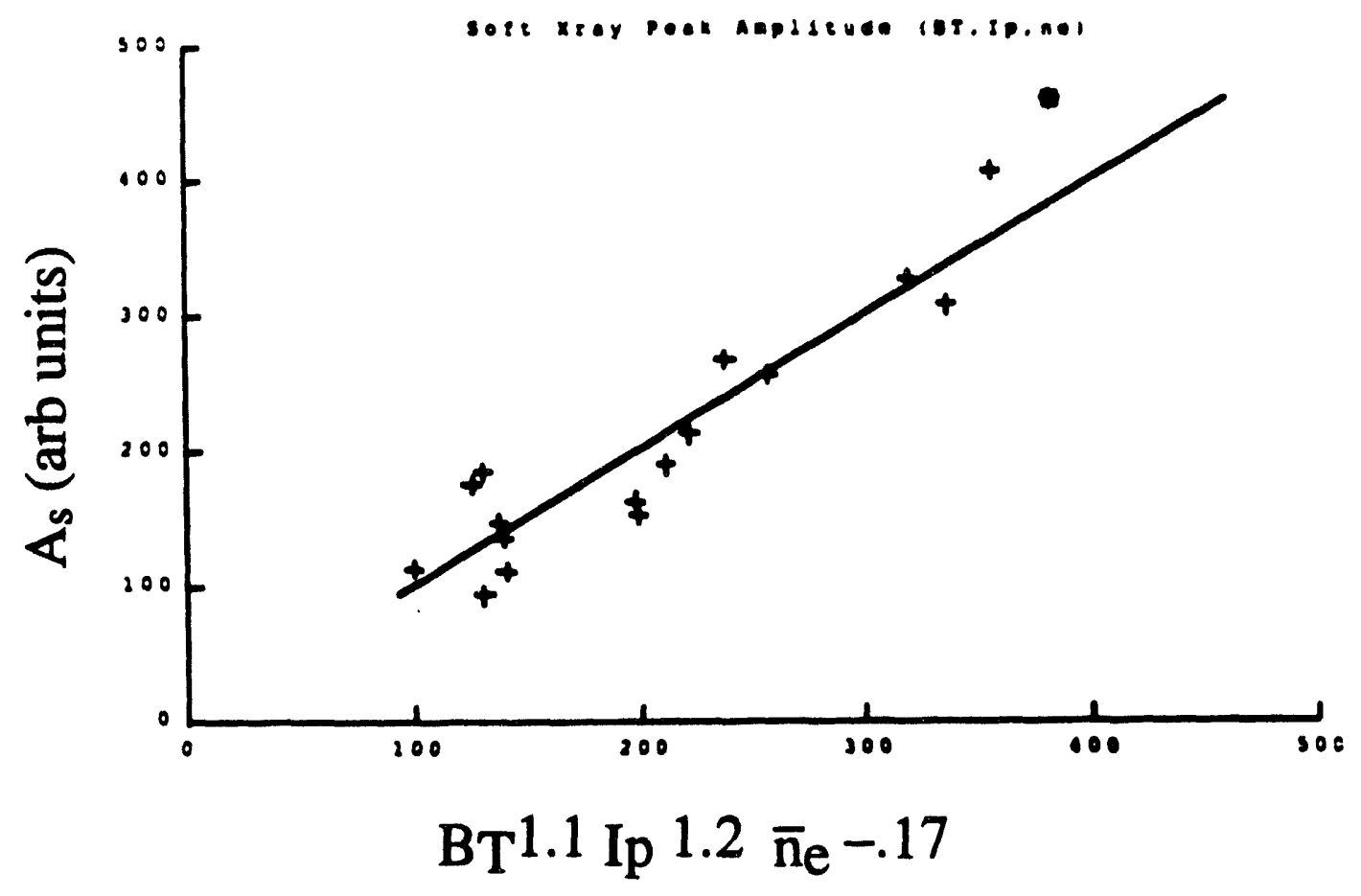

Soft X-ray Profile Width (HWHM)

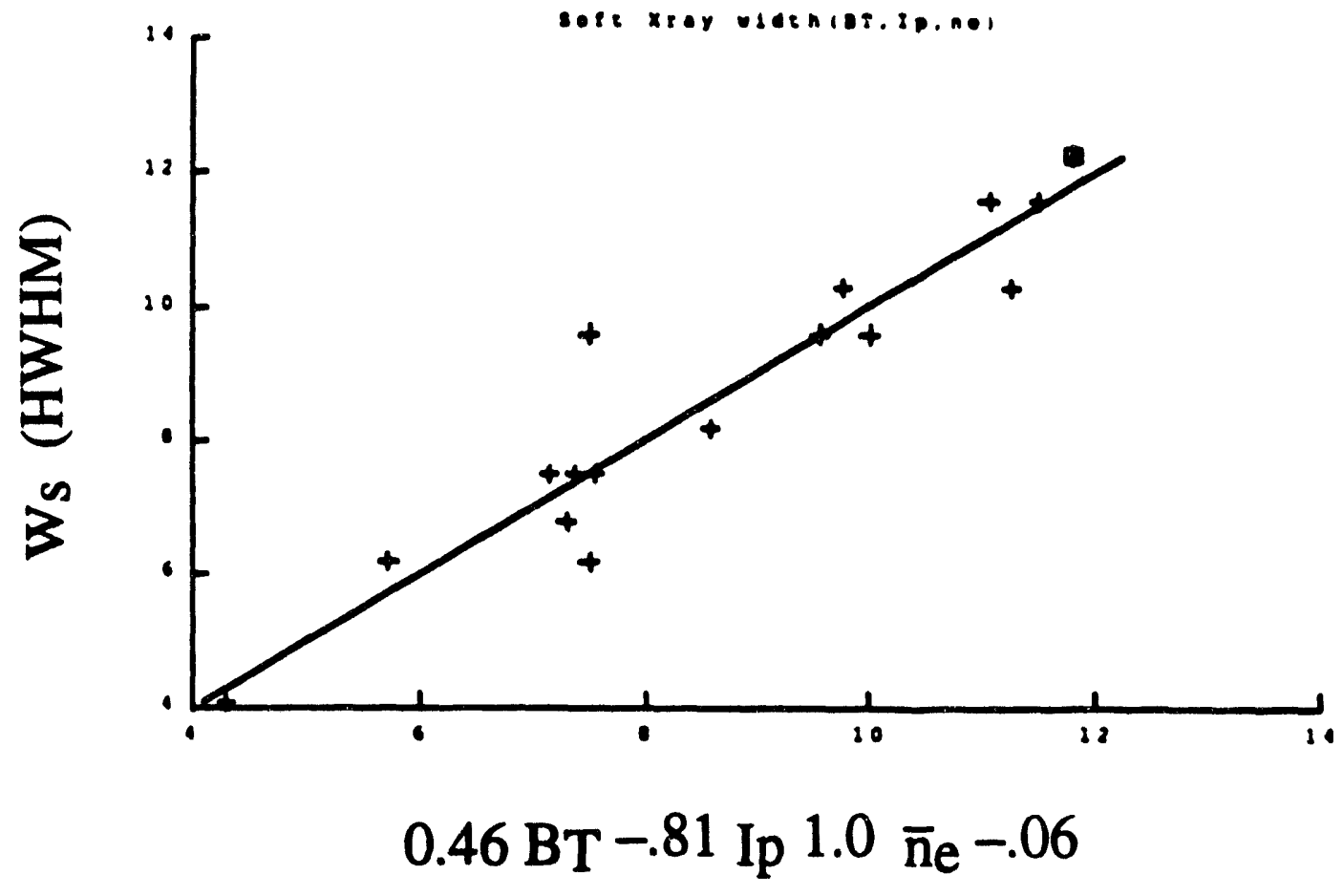

Fig. 11 Soft x-ray profile regression for (a) peak amplitude $A_{s}$, and (b) width at HWHM ws, for a power law of BT, Ip, ne. 


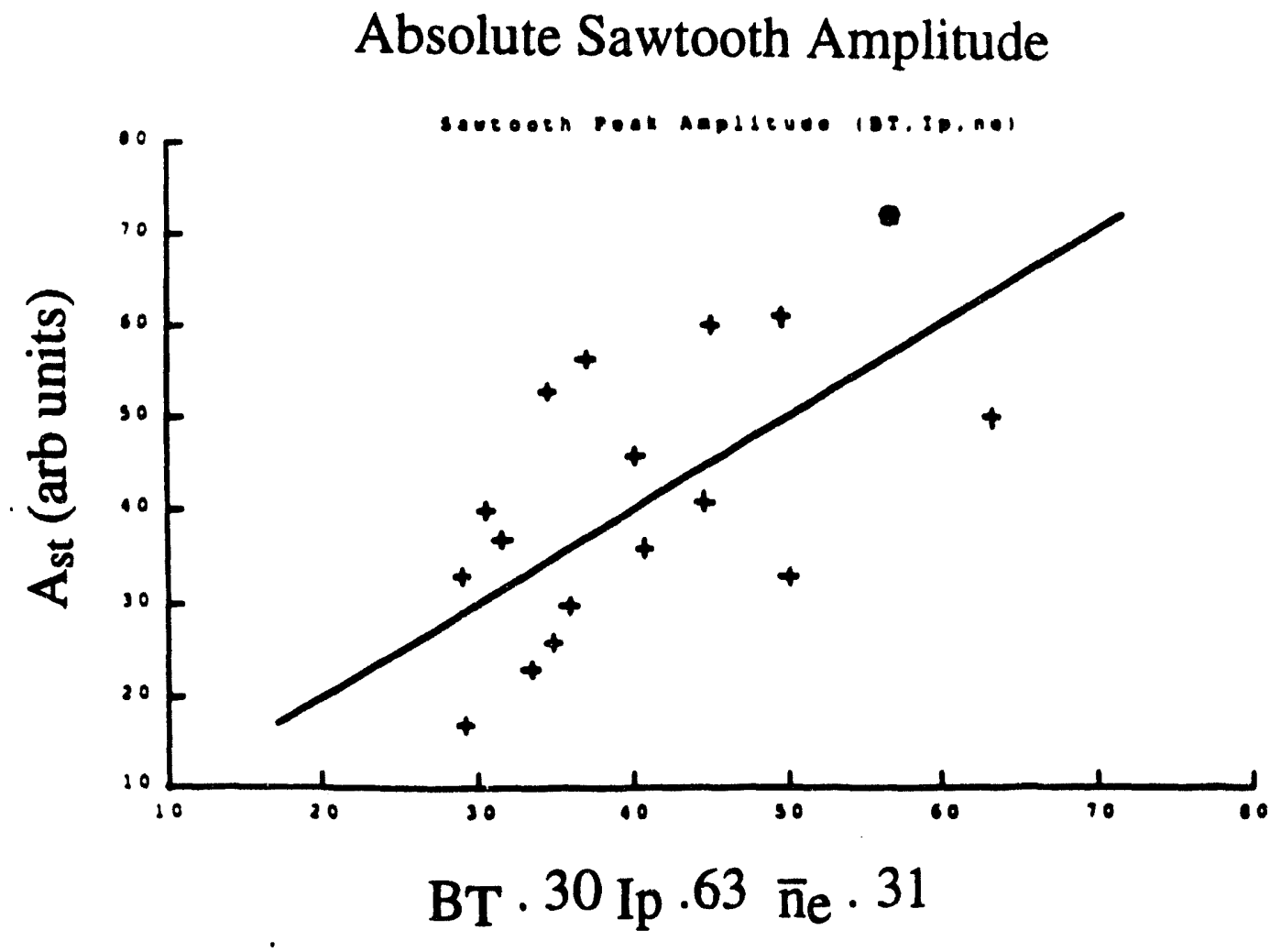

Normalized Sawtooth Amplitude

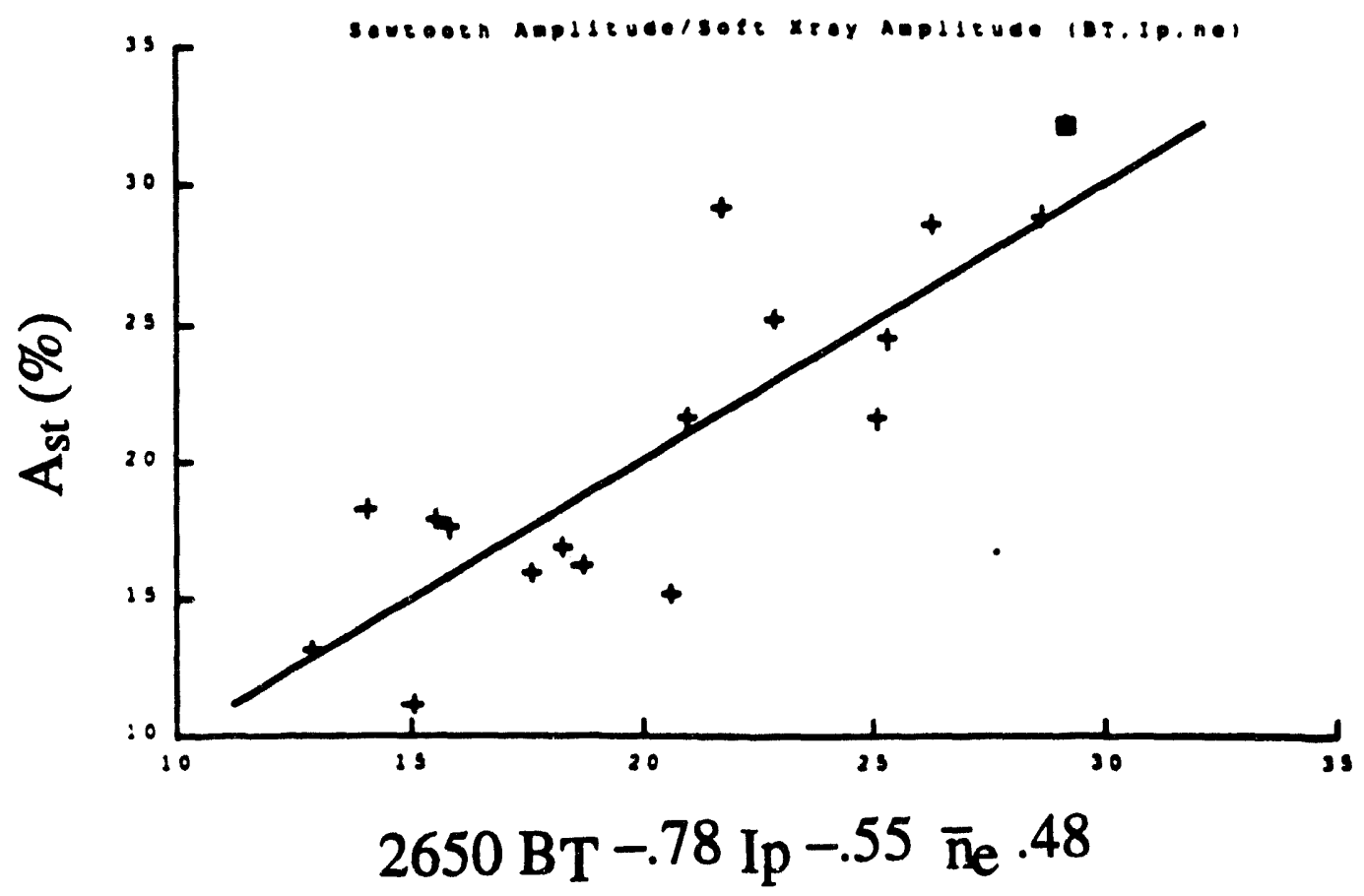

Fig. 12 Soft $x$-ray sawtooth regression for (a) absolute sawtooth amplitude $A_{\text {st }}$, and (b) normalized sawtooth amplitude $A_{s t} / A_{s}$, for a power law of BT, Ip, $\bar{n}_{\mathbf{e}}$. 

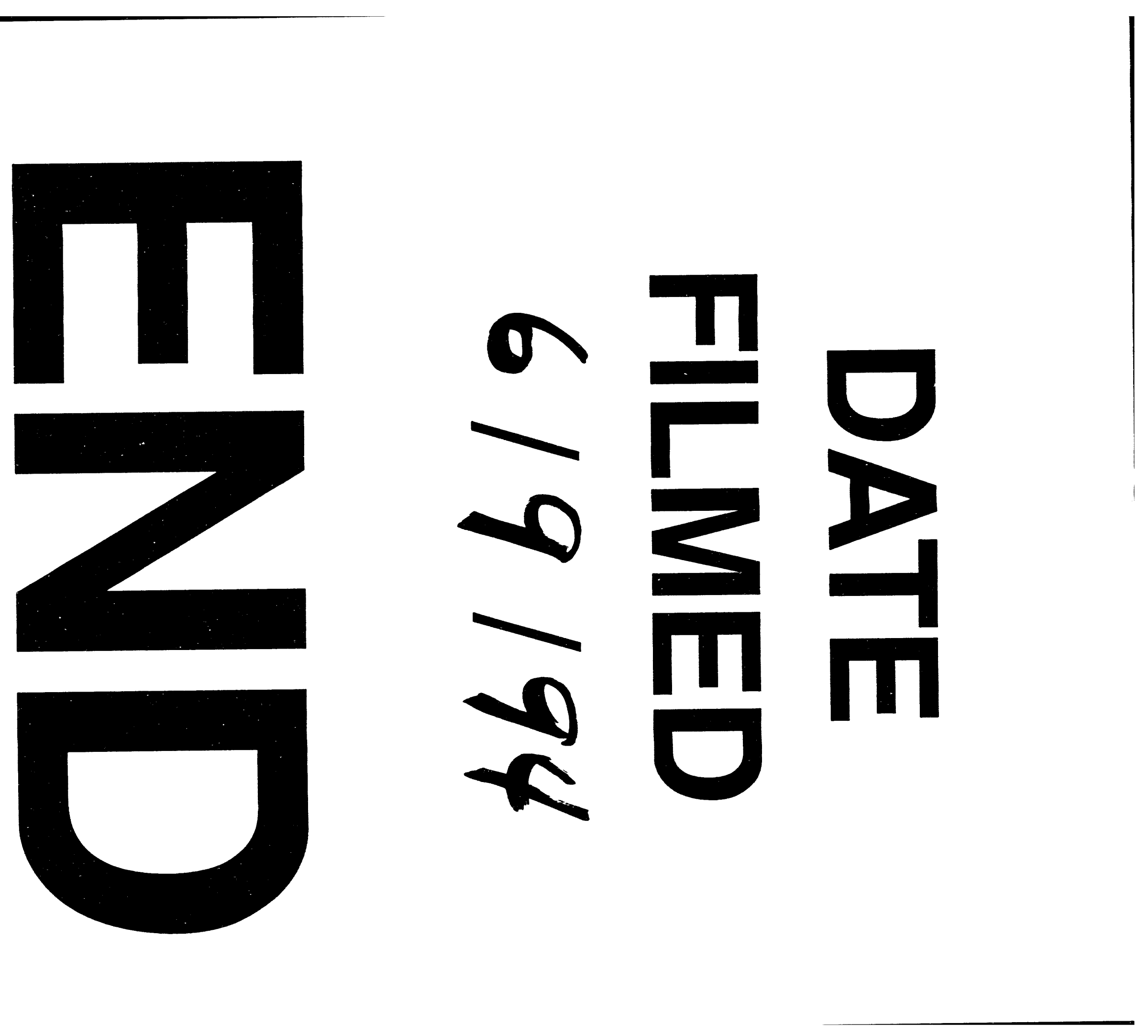
$m$ $\sqrt{-2}$

(1)

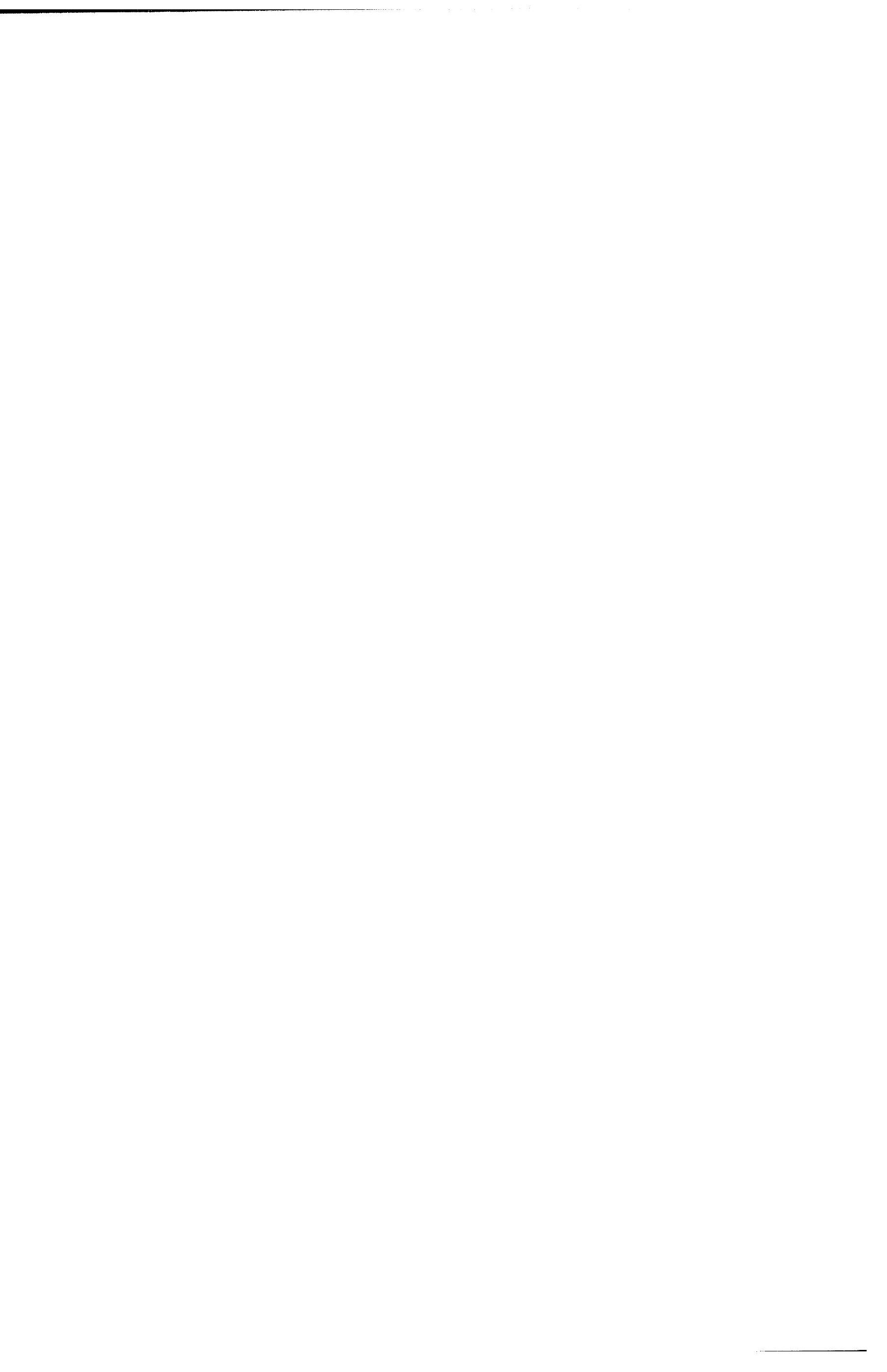

